\title{
Escudo azul y el amparo del patrimonio en situación crítica, una asignatura pendiente
}

\begin{abstract}
En 1954, como consecuencia de la destrucción masiva de numerosos bienes culturales durante la Segunda Guerra Mundial, se aprobaba en La Haya una Convención para la Protección de los Bienes Culturales en caso de Conflicto Armado. Era el primer tratado internacional de estas características. En 1996 se funda el Comité Internacional del Escudo Azul (The International Comittee of the Blue Shield, ICBS) organización internacional que nace como guardián de los principios de la citada Convención. El ICBS conforma una red internacional de expertos en patrimonio cultural siempre disponibles para aconsejar y ayudar en caso de conflictos o desastres naturales. Algunas de sus actuaciones más notorias en los últimos años han sido la denuncia y asistencia con motivo de la destrucción de los Budas en Afganistán, las inundaciones en Praga, el incendio y saqueo del Museo de Bagdad y la Biblioteca Nacional durante la guerra de Irak, y los devastadores efectos del terremoto en Haití sobre el patrimonio cultural del país caribeño. A finales de 2013 se constituía el Comité Nacional del Escudo Azul en España, que preside por turno Luis Grau Lobo, director del museo de León.
\end{abstract}

Luis Grau Lobo | presidente de ICOM-España y presidente por turno del comité español de Escudo Azul

URL de la contribución <www.iaph.es/revistaph/index.php/revistaph/article/view/3675>

A mediados del siglo IV antes de nuestra Era, Eróstrato de Éfeso buscó la notoriedad a costa de destruir un legado único, el templo de Diana en esa ciudad griega del Asia menor. Dos milenios y medio más tarde, milicias yihadistas de Daesh han conducido excavadoras y esgrimido martillos pilones contra el corazón de las viejas ciudades de Mesopotamia, en el paisaje que conoció el alba de nuestra civilización. Aparte del odio, el resentimiento y la provocación, el objetivo de estos bárbaros también participa de ese erostratismo, del afán de pasar a la posteridad como agentes de destrucción de algo irremplazable; no como creadores, sino como parásitos de la creación. Fagocitan la fama inmortal de un lugar para existir en ella eternamente, bajo la vitola de ser sus liquidadores. Como el magnicida, el calibre del acto ha de otorgar a su nombre renombre eterno. El de Eróstrato intentó silenciarse tras conocer su propósito: es evidente que no se logró. Y cuanto más se difunda tamaña infamia, más destrozos se producirán; es inevitable. Como si no hubiera una aterradora lógica en algo así por parte de unos sádicos que cortan cabezas y lo graban para pública exhibición...

Desde que el mundo es mundo, la iconoclasia ha acompañado el dominio sobre nuevos territorios: la elimi- nación de símbolos previos y la destrucción del otro, la damnatio memoriae, definen cualquier poder y son directamente proporcionales a su grado de despotismo. De ahí esa saña.

Por otra parte, las guerras golpean siempre con más fuerza a los más débiles. Y, aparte de las personas, claro está, los bienes más delicados son aquellos que precisamente han llegado hasta nosotros atravesando guerras, la incuria de los hombres y la erosión del tiempo. Reconocer esos bienes como patrimonio común y colectivo es una de las conquistas intelectuales de la modernidad, protegerlos incluso en las circunstancias más arduas es tarea de sociedades maduras y consecuentes.

Hace cien años, Europa se estremeció a sí misma con las atrocidades de las trincheras. Poco después, redobló su nivel de sadismo en la guerra más sangrienta que jamás existió. Y en ella, los bombardeos y el pillaje de obras de arte cuestionaron también a quienes se habían tenido hasta entonces por sociedades civilizadas. Para recuperar la autoestima, para evitar en lo posible situaciones de esta naturaleza, la Convención de La Haya (1954, y su segundo protocolo de 1999) vino a regular 
la protección de los bienes culturales en caso de hostilidades, ocupación u otras situaciones conflictivas, prohibiendo su uso como arma ideológica. Infelizmente, es un tema de moda. Y no por la película Monuments men (superada con creces por aquella, El Tren, de 1964), sino por la infausta serie que comenzó en la biblioteca de Sarajevo, siguió con los budas de Bamiyán y ha llegado hasta las ruinas de Palmira. O los innumerables desastres, de los incendios de Valparaíso al sismo que ha arrasado la arquitectura nepalí.

Entre las iniciativas señaladas para llevar a cabo el mandato de La Haya, la organización Escudo Azul está considerada el equivalente de la Cruz Roja en el terreno cultural. Fundada por las cuatro organizaciones principales no gubernamentales relacionadas con el patrimonio: el Consejo Internacional de Archivos (ICA), el Consejo Internacional de Museos (ICOM), el Consejo Internacional de Monumentos y Sitios (ICOMOS) y la Federación Internacional de Asociaciones de Bibliotecarios y Bibliotecas (IFLA), su funciones interesan al asesoramiento a los gobiernos para una mejor previsión y gestión de los momentos críticos y a la asistencia a territorios en conflicto para proteger los bienes culturales en el marco de UNESCO y la Convención.

Pero no sólo son los enfrentamientos bélicos, también Escudo Azul se ocupa de las situaciones de peligro patrimonial en caso de catástrofes naturales, por desgracia circunstancias más imprevisibles y, en ciertos casos, crecientes (como las climáticas), que exigen medidas similares en muchos casos. Varios son los terrenos donde estas acciones pueden resultar decisivas, pues es bien sabido que ante una situación de riesgo repentino o grave, saber qué hacer y hacerlo con método puede resultar determinante, mientras que una operación errónea puede acabar por ser más destructiva que la propia causa. Actividades como la coordinación de agentes implicados (mando unificado), la formalización de protocolos, la formación de fuerzas del orden y/o del ejército en colaboración con organizaciones internacionales, la disposición de listados de bienes culturales y sus condicionantes, la planificación de medios, la implicación de profesionales especializados, la evaluación de planes de emergencia y sus medidas correctoras, etc. En

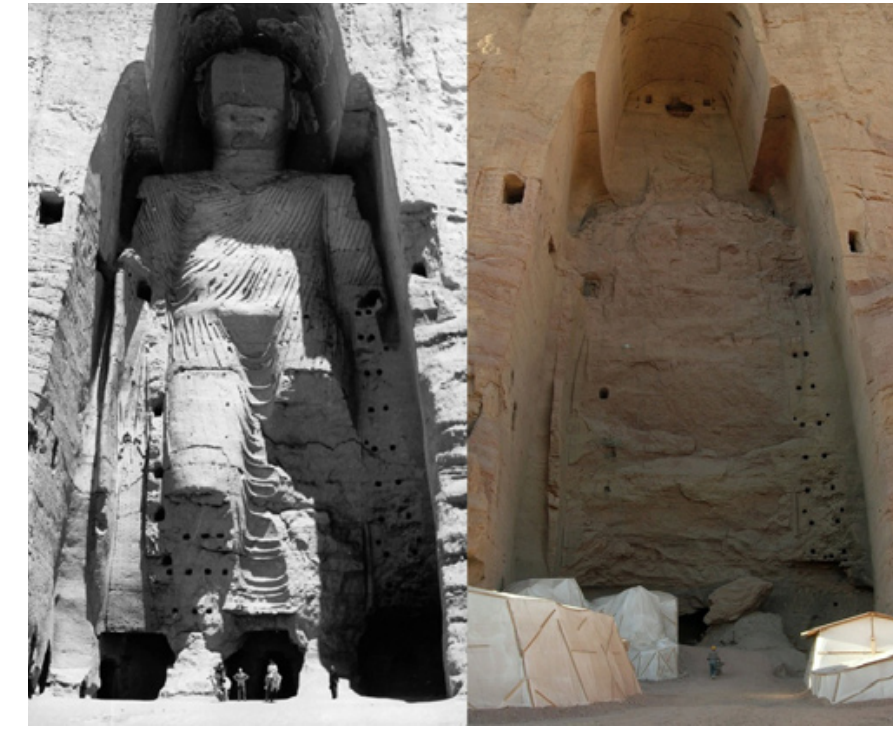

Budas de Bamiyán, en 1963 y 2008, después de su destrucción | fotos Wikipedia commons: UNESCO/A Lezine

el contexto de sus atribuciones, el ICOM ha elaborado el Programa de emergencia en los museos, MEP por sus siglas inglesas, destinado a la planificación de urgencias e intervenciones. Está dirigido a los profesionales de museos y a los sectores implicados en toda emergencia (bomberos, policía, asociaciones humanitarias, etc.). Puesto que los condicionantes locales son decisivos, el programa pretende adaptarse a las necesidades de cada entorno, examinando el terreno e involucrando a los profesionales para lograr las estrategias de intervención más eficaces, el proceso de gestión de riesgos y una formación continua. El Programa ha sido ya implementado en el sudeste asiático (2005) y los Balcanes (2006).

Como sucede con ICOM entre otros, el Escudo Azul se organiza en comités nacionales. Algunos de ellos con una larga tradición de acción local o regional, otros (incluso en países muy desarrollados) sorprendentemente jóvenes. En septiembre de 2013, a iniciativa del Ministerio de Educación, Cultura y Deporte (que se ha señalado como una de las administraciones más preocupadas en estos temas con recientes publicaciones de referencia), una reunión en la sede del IPHE congregó a distintos protagonistas llamados a constituir el comité español del Escudo Azul, inexistente hasta 


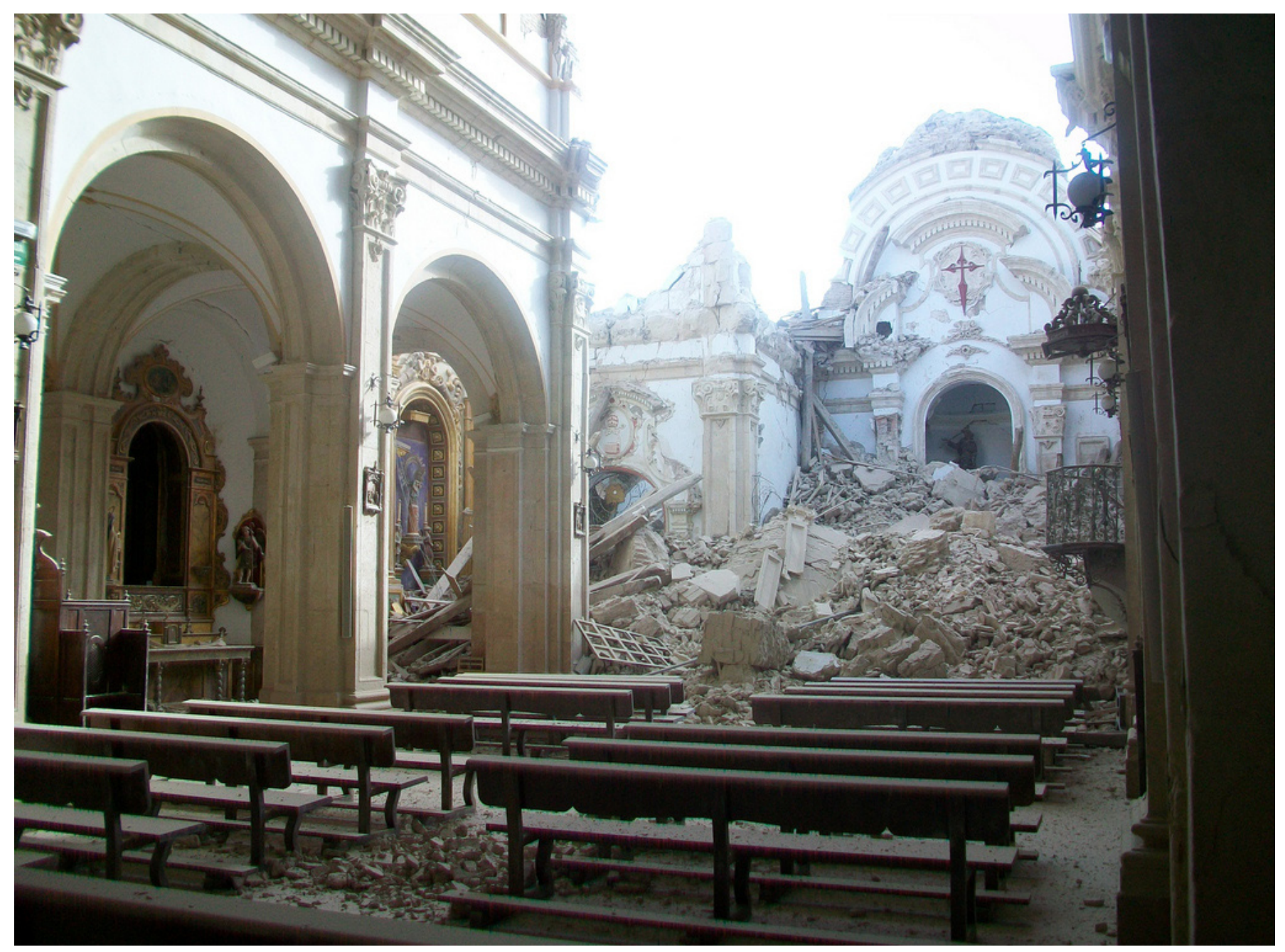

Iglesia de Santiago en Lorca después del terremoto del 11 de mayo de 2011 | foto Wikipedia commons: Antonio Periago

entonces. Se decidió en esa ocasión que fuera ICOMEspaña quien tuviera la primera presidencia por turnos y que el Ministerio se hiciera cargo de timón y financiación. La iniciativa a la que acudió mi antecesora (Sofía Rodríguez Bernis) fue alentaba por las consecuencias del cercano terremoto de Lorca, que, de cierta manera, reavivó la conciencia de que España no era un país tan ajeno a la posibilidad de una destrucción traumática de patrimonio y cabía plantearse la adopción de medidas coordinadas para minimizar tales riesgos. Sin embargo, dos años después poco más se ha hecho. En estos días ICOM España insiste en la necesidad de dar sentido a esa organización, como paso previo a la adopción de medidas que puedan paliar una infinidad de contin- gencias cuyo calado siempre se nos ha de escapar. No sólo en España, sino también en misiones que, como las de otras ONG y organizaciones de apoyo humanitario, llevan a nuestro país a prestar ayuda en lugares a veces remotos. La participación de las comunidades autónomas y otras administraciones, y de los muy diversos agentes vinculados a la protección del legado que tanto nos importa, exigen una acción resuelta que sólo los poderes públicos pueden promover con la necesaria determinación y medios. Esperemos, por ello, que el Escudo azul español no tenga que actuar nunca pero esté preparado para hacerlo, donde y cuando sea. 